\title{
Flexible HR Practice
}

\author{
Umesh K. Bamel ${ }^{1} \cdot$ Peter Stokes $^{2}$
}

Received: 2 February 2016/Accepted: 5 February 2016/Published online: 26 February 2016

(C) Global Institute of Flexible Systems Management 2016

Research on the concept of 'flexibility' has produced a substantive scholarly in recent decades and has evolved as a focal area of management research (Mønsted 1991; Sushil 1994; Skipper et al. 2014; Krishna et al. 2015). According to Sushil (2001) 'Flexibility offers freedom of choice and is highly context specific'. Here, 'context specific' refers to the role of contingencies within flexibility which might render it as a form of a firm's dynamic capability. The dynamic capability scholarship argues that in order to achieve excellence, organizations should develop capabilities complementary to their competencies (Teece et al. 1997; Helfat and Peteraf 2009). Thus, flexible HR practices can help organizations in achieving sustainable competitiveness through creating, integrating, reconfiguring, and building on its human resource base. For example, organizations can achieve competitive edge by customizing training and development programs.

Conventionally, flexibility has had a comparatively peripheral presence in human resource and organizational behavior research. Although, some pockets of research are able to be evidenced on a few areas related to HRM, for example: behavioral flexibility (Lindberg and Kaiser 2004), managerial/people flexibility (Jones et al. 2006; Verdú and Gómez-Gras 2009; Bamel et al. 2013, 2014), flexible pay

Umesh K. Bamel

umeshbamel@gmail.com; umeshbamel@iimraipur.ac.in

Peter Stokes

p.stokes@chester.ac.uk

1 Indian Institute of Management Raipur, Sejbahar, Raipur 492015, India

2 Chester Business School, University of Chester, Chester CH14BJ, UK structure (Riley and Lockwood 1997), labor flexibility (Karuppan 2004; Mihail 2004) and flexible human resource deployment (Forrier and Sels 2003), in general, this area is marginalized. In contrast, a wide span of HR functions and practices such as: flexible recruitment and selection, flexible career and succession planning, flexible pay structure, creating organizational structure and design which incorporate flexible HR practices have received considerably less attention. This special issue is therefore timely and this is underpinned by Prof. Sushil, Editor-In-Chief, Global Journal of Flexible Systems Management, who has commented (2015):

organizations need to customize their employee services and offerings so that these services and offerings would address the employees' needs. This will certainly result in more satisfied, motivated and productive workforce. Therefore there is a need for an extended scholarly examination of flexibility in HR practices and functions i.e. forms of flexibility in HR practices, designing and employing flexible HR practices, significance of flexible HR practices to organizations and also to individuals, and other related issues.

Thus, in response to the idea of "Flexibility in HR Practices", the Global Journal of Flexible Systems Management has developed this special issue in order to stimulate intellectual debate on concerns related to flexible HR practices. The agenda of this special issue is aimed at advancing the scholarly debate and discussion on flexible HR practices and, in response, presents six research papers which explore the various aspects of flexibility in human resource management. In addition, these papers are complemented by two short communications which present 
important and valuable practitioner perspectives on the scope of on flexible HR practices in organizations.

The first paper of the special issue is an empirical paper, which examines the relationship between workplace flexibility and work family enrichment in an Indian context. The authors (Rastogi, Rangnekar and Rastogi) discuss the implications of operational and temporal flexibility on nonwork domain i.e. family life. The paper suggests that the flexible workplace dimensions exert positive influence between work and family interaction and thus these may help organizations in their talent management endeavor.

The second paper of the special issue is titled "Chinese Leadership and Its Impacts on Innovative Work Behavior of Thai Employees" (Piansoongnern). This paper investigates Thai employees' perceptions on their Chinese superiors and seeks to comprehend how Chinese leadership impacts on innovative work behavior of the Thai employees. The paper also suggests the implications for practitioners.

The subsequent paper, authored by Yadav, is entitled "A Flexible Management Approach for Globally Distributed Software Projects". This paper discusses the concerns and challenges related to managing the distributed work in globalized environment. It suggests flexibility based managerial practice to address the challenges of distributed works and projects.

The fourth paper in this issue is "Workplace Flexibility dimensions as Enablers of Organizational Citizenship Behavior" by Yadav, Rangnekar and Bamel. This paper establishes six dimensions of workplace flexibility as enablers of organizational citizenship behavior in Indian organizations. The paper suggests potent ways of advancing the organizational citizenship behavior.

The next paper: "A study of HR flexibility and firm performance: A perspective from IT industries" is authored by Sekhar, Patwardhan and Vyas. This paper assesses causal relationships between the dimensions of HR-flexibility and firm performance in Indian IT industry using DEMATEL method. HR flexibility appreciates diversity and individuality, shared responsibility, and wholeness at workplace. It also helps organization in work scheduling and career management.

The sixth paper of the special issue is "Workflow Development Effort Estimation as Applied to Web Human Resource Management". The authors (Raheem and Altmann) suggest the proximity scoring measurement method to determine workflow size and to estimate workflow development effort with its knowledge retention effort. Potential implications of precise measurement of workflow are also discussed.

The first short communication is by Peter Shaw founding partner of Praesta Partners, UK which talks about focused individual and team coaching as exemplars of flexible HR practices. This communication reveals the implications of focused coaching during crises or adverse times.

The second short communication is by Prashant Srivastava, President Human Capital, Reliance Group (ADA). Mr. Srivastava emphasizes that in order meet the changing demands of markets and customers and to align the businesses with dynamic environment, HR has to enable the strategies and business plans i.e. it has to be dynamic and flexible.

Conclusively, the six research papers and the two practitioner's short communications provide new perspectives on flexibility in HR practices. These papers work to extend our understanding on the implications of flexible HR practices in contemporary work environments.

\section{References}

Bamel, U. K., Rangnekar, S., \& Rastogi, R. (2014). Do gender, position and type of organization shape human resource flexibility? In M. K. Nandakumar (Ed.), Organisational flexibility and competitiveness, flexible systems management. India: Springer. doi:10.1007/978-81-322-1668-1_9.

Bamel, U. K., Rangnekar, S., Rastogi, R., \& Kumar, S. (2013). Organizational process as antecedent of managerial flexibility. Global Journal of Flexible Systems Management, 14(1), 3-15.

Forrier, A., \& Sels, L. (2003). Flexibility, turnover and training. International Journal of Manpower, 24(2), 148-168.

Helfat, C. E., \& Peteraf, M. A. (2009). Understanding dynamic capabilities: Progress along a developmental path. Strategic Organization, 7(1), 91-102.

Jones, R. A., Rafferty, A. E., \& Griffin, M. A. (2006). The executive coaching trend: Towards more flexible executives. Leadership \& Organization Development Journal, 27(7), 584-596.

Karuppan, C. M. (2004). Strategies to foster labor flexibility. International Journal of Productivity and Performance Management, 53(6), 532-547.

Krishna, V. M., Prakash, G., \& Manikandan, M. (2015). Congregating or Swerving? Developmental trends and changing role of Indian organizational flexibility along globalization process. ProcediaSocial and Behavioral Sciences, 189, 64-80.

Lindberg, J. T. \& Kaiser, R. B. (2004). Assessing the behavioral flexibility of managers: A comparison of methods, poster session presented at the 19th annual meeting of the Society for Industrial and Organizational Psychology in Chicago, IL, April 2004.

Mihail, D. M. (2004). Labour flexibility in Greek SMEs. Personnel Review, 33(5), 549-560.

Mønsted, M. (1991). Flexbility and skills in small enterprises. Entrepreneurship \& Regional Development, 3(2), 101-110.

Riley, M., \& Lockwood, A. (1997). Strategies and measurement for workforce flexibility: An application of functional flexibility in a service setting. International Journal of Operations \& Production Management, 17(4), 413-419.

Skipper, J. B., Hall, D. J., Hazen, B. T., \& Hanna, J. B. (2014). Achieving flexibility via contingency planning activities in the supply chain. International Journal of Information Systems and Supply Chain Management (IJISSCM), 7(2), 1-21.

Sushil, (1994). Flexible systems methodology. Systems Practice, 7(6), 633-652. 
Sushil, (2001). Demythifying flexibility. Management Decision, 39(10), 860-865.

Teece, D. J., Pisano, G., \& Shuen, A. (1997). Dynamic capabilities and strategic management. Strategic Management Journal, 18(7), 509-533.

Verdú, A. J., \& Gómez-Gras, J.-M. (2009). Measuring the organizational responsiveness through managerial flexibility. Journal of Organizational Change Management, 22(6), 668-690.

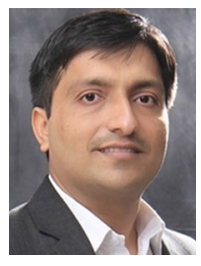

Umesh K. Bamel is faculty in OB and HR Group at Indian Institute of Management Raipur. He is a doctorate in $\mathrm{OB}$ and HR from Indian Institute of Technology Roorkee, India. His doctorate research is the winner of highly commendable $\mathrm{PhD}$ thesis award 2013 in Leadership and Organizational Development Category by European Foundation for Management Development and Emerald. His research has appeared in the classified and peer reviewed journals for example, Journal of Management Development, Vine: Journal of
Information and Knowledge Management, International Journal of Organizational Analysis, Decision, Global Journal of Flexible System management.

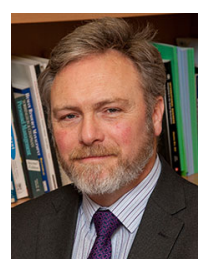

Peter Stokes is Deputy Dean of the University of Chester Business School, United Kingdom Professor Stokes is Editor-in-Chief of the International Journal of Organizational Analysis and serves on a number of journal boards including the EuroMed Journal of Business. He holds a number of positions on international bodies including Fellow and UK Country Director for the EuroMed Business Research Institute, Track Chair for the Sustainable and Responsible Business Special Interest Group of the British Academy of Management and UK Ambassador for the Association de Gestion des Ressources Humaines (French Academic HR Association). He has been visiting lecturer and academic advisor at universities and institutes in France, Holland, Spain, Ireland, Germany, Senegal (West Africa),Vietnam, Morocco, Hong Kong, China, India and Dubai. 